\title{
Neuroprotective effects of Scrophularia buergeriana extract against glutamate-induced toxicity in SH-SY5Y cells
}

\author{
HAE JIN LEE ${ }^{1}$, DEMETRIOS A. SPANDIDOS ${ }^{2}$, ARISTIDIS TSATSAKIS ${ }^{3,4}$, DENISA MARGINA ${ }^{5}$, \\ BORIS N. IZOTOV ${ }^{4}$ and SEUNG HWAN YANG ${ }^{1}$
}

\author{
${ }^{1}$ Department of Biotechnology, Chonnam National University, Yeosu 59626, Republic of Korea; ${ }^{2}$ Laboratory of Clinical Virology, \\ and ${ }^{3}$ Department of Toxicology and Forensics, School of Medicine, University of Crete, Heraklion 71003, Greece; \\ ${ }^{4}$ Department of Analytical and Forensic Medical Toxicology, Sechenov University, Moscow 119991, Russia; \\ ${ }^{5}$ Department of Biochemistry, Carol Davila University of Medicine and Pharmacy, \\ Faculty of Pharmacy, Bucharest 020956, Romania
}

Received February 5, 2019; Accepted March 15, 2019

DOI: $10.3892 /$ ijmm.2019.4139

\begin{abstract}
The aim of this study was to investigate the antioxidant and anti-apoptotic activities, as well as the underlying mechanisms of action, of Scrophularia buergeriana (S. buergeriana) extract (SBE) in glutamate-induced SH-SY5Y cell death. The roots of $S$. buergeriana were extracted with $70 \%$ ethanol, and standardized SBE was used in this study. To induce cytotoxicity, the SH-SY5Y cells were exposed to glutamate for $3 \mathrm{~h}$, or pre-treated with SBE for $1 \mathrm{~h}$, and subsequently incubated with glutamate for $3 \mathrm{~h}$. The neuroprotective effects were assessed by measuring cell viability and the total glutathione contents using commercial kits. The antioxidant and anti-apoptotic mechanisms of action of SBE were evaluated by western blot analysis. The results confirmed that glutamate-induced toxicity was caused by reactive oxygen species (ROS) production, leading to oxidative stress and DNA damage, thus leading to cell death. However, treatment of the SH-SY5Y cells with SBE significantly increased the viability of the cells exposed to glutamate by upregulating the levels of antioxidant proteins, such as superoxide dismutase (SOD)1, SOD2 and glutathione peroxidase-1 (GPx-1), and directly enhancing the total glutathione contents. Furthermore, SBE attenuated DNA impairment and decreased B-cell lymphoma-2 (Bcl-2)-associated X protein (Bax), cleaved caspase-3 and cleaved poly(adenosine diphosphate (ADP)-ribose) polymerase (PARP) activation. In addition, SBE upregulated Bcl-2
\end{abstract}

Correspondence to: Professor Aristidis Tsatsakis, Department of Toxicology and Forensics, School of Medicine, University of Crete, Heraklion 71003, Greece

E-mail: tsatsaka@uoc.gr

Dr Seung Hwan Yang, Department of Biotechnology, Chonnam National University, Yeosu 59626, Republic of Korea

E-mail: ymichigan@jnu.ac.kr

Key words: glutamate, Scropularia buergeriana, oxidative stress, anti-apoptotic, $\mathrm{SH}-\mathrm{SY} 5 \mathrm{Y}$ cells expression via 38 mitogen-activated protein kinases (MAPKs). On the whole, the findings of this study demonstrated that SBE exerts neuroprotective effects against glutamate-induced cell toxicity through its antioxidant and anti-apoptotic activities.

\section{Introduction}

Glutamate is known as an excitatory neurotransmitter and plays a crucial role in the plasticity of the central nervous system (CNS) $(1,2)$. When the glutamate concentration is abnormally high, it functions as a neurotoxin and leads to cell death (3). Excessive glutamate levels damage cellulr components, including the mitochondria, and promote the generation of reactive oxygen species (ROS) and induce cell death (4). Neuronal cell loss associated with glutamate neurotoxicity is associated with certain neurological diseases, such as stroke or trauma, as well as Alzheimer's, Parkinson's and Huntington's diseases (5-9).

Cells may be protected from oxidative injury by antioxidant systems. Some intracellular ROS may be counteracted by superoxide dismutases (SODs), a group of vital antioxidant enzymes, which include SOD1 and SOD2, as well as by glutathione peroxidase (GPx-1) $(10,11)$. Metal-containing SODs play a role in scavenging ROS and facilitate catalytic activity through the use of copper/zinc $(\mathrm{Cu} / \mathrm{Zn})$ or manganese (Mn) (12). SOD1 is a $\mathrm{Cu} / \mathrm{Zn}$-containing enzyme that is located in cytosolic compartments. Low SOD1 levels are associated with increased ROS levels, which triggers oxidative damage to cellular components, including to DNA, and the functions of SOD1 are protect the CNS from damage. The Mn-containing enzyme, SOD2, is located in the mitochondrial matrix and may protect mitochondrial DNA from oxidative damage $(10,12)$. GPx-1 is a major enzyme that protects the cells from lethal oxidative stress by converting $\mathrm{H}_{2} \mathrm{O}_{2}$ to $\mathrm{H}_{2} \mathrm{O}$ with reduced glutathione (GSH) as a co-factor (13).

Glutathione is a major cellular oxidant that protects cells from free radical damage and exists in both reduced (GSH) and oxidized forms (GSSG). The reduced form is predominant within the cell and represents $>99 \%$ of total glutathione 
contents (14). Prolonged oxidative glutamate toxicity causes glutathione depletion in neurons, and leads to oxidative stress and to the development of neurodegenerative disorders $(15,16)$. The formation of excessive oxidative stress also activates mitogen-activated protein kinases (MAPKs), and results in cell damage and apoptosis. Therefore, it is important to identify antioxidants that protect neuronal cells from free radical damage and inhibit cell death.

MAPKs are serine-threonine protein kinases that regulate a variety of cellular activities, such as cell proliferation, differentiation, survival and death $(17,18)$. The MAPK family is composed of extracellular signal-regulated kinases (ERKs), stress-activated c-Jun N-terminal kinases (JNKs)/stress-activated protein kinases and p38 kinases (19). Among these, p38 MAPKs play important roles in mediating apoptotic pathways (20). Glutamate-induced oxidative stress may activate p38 MAPKs (21) and activated p38 kinase may induce apoptosis by regulating caspases (22).

Scrophularia buergeriana (SB) is known as Hyun-Sam in Korea and is traditionally used to treat fever, swelling, constipation and age-related memory loss in Northern China (23). The dried root of SB possesses compounds, such as phenylpropanoids (24), 7-harpagide-type iridoids (25), E-harpagoside, 8-O-E-p-methoxycinnamoylharpagide (MCA-Hg) (26) and E-p-methoxycinnamic acid (27), which display neuroprotective activities. However, food and medicines cannot be evaluated as whole materials and are instead fractionated into organic solvents for analysis. In a previous study, the ethanolic extract of SB (SBE) was found to exhibit cognitive-enhancing and antioxidant activities. However, the effects of SBE on cells have not yet been associated with the p38 MAPK pathway and anti-apoptotic mechanisms, at least to the best of our knowledge. Therefore, in this study, we investigated whether SBE reduces oxidative stress and exerts neuroprotective effects against glutamate-induced neurotoxicity via antioxidant and anti-apoptotic mechanisms in SH-SY5Y cells.

\section{Materials and methods}

Sample preparation. The SBE extraction process was as follows and as previously described (18): The pieces of 3-10 cm cut dried roots of SB obtained from Nutrapharmtec (Seongnam, Korea) were extracted with $70 \% \mathrm{EtOH}$. The ratio between the dried extract and solvent was 1:8 and the extraction proceeded for $2 \mathrm{~h}$ at $90^{\circ} \mathrm{C}$ before filtering. The extracts were then concentrated in a vacuum evaporator and the concentrate was sterilized and cooled. The residue was dried, and a powder was obtained. The standardized SBE sample was dissolved in dimethyl sulfoxide (DMSO) prior to use.

Cells and cell culture. The SH-SY5Y human neuroblastoma cells used in this study were purchased from the American Type Culture Collection (ATCC, Manassas, VA, USA; CRL-2266) and were authenticated via a short tandem repeat (STR) profiling service provided by ATCC. The cells were cultured in Dulbecco's modified Eagle's medium (DMEM; GE Healthcare Life Sciences, Logan, UT, USA) supplemented with $10 \%$ fetal bovine serum (FBS) and 1\% antibiotics (both from Life Technologies; Thermo Fisher Scientific, Waltham, MA, USA) containing $100 \mathrm{U} / \mathrm{ml}$ penicillin and $100 \mathrm{~g} / \mathrm{ml}$ streptomycin.
The cells were incubated for $24 \mathrm{~h}$ at $37^{\circ} \mathrm{C}$ in a humidified incubator with $5 \% \mathrm{CO}_{2}$.

Cell cytotoxicity assay. The SH-SY5Y cells were seeded in 96-well plates at a density of $5 \times 10^{4}$ cells/well and incubated for $24 \mathrm{~h}$. The following day, the cells were pre-treated with various concentrations $(125,250$ or $500 \mu \mathrm{g} / \mathrm{ml})$ of SBE for $1 \mathrm{~h}$ and then exposed to $100 \mathrm{mM}$ glutamate (Wako, Osaka, Japan) for $3 \mathrm{~h}$ with or without SBE. Sample stock solution was prepared $(125,250$ and $500 \mathrm{mg} / \mathrm{ml})$ and diluted $1 / 1,000$ in the medium to allow the working concentration $(125,250$ and $500 \mu \mathrm{g} / \mathrm{ml}$ ) to be processed. Following a 3-h incubation period at $37^{\circ} \mathrm{C}$ with $5 \% \mathrm{CO}_{2}$ conditions, $10 \mu \mathrm{l}$ cell viability assay reagent (DoGenBio, Seoul, Korea) was added and the cells were incubated at $37^{\circ} \mathrm{C}$ with $5 \% \mathrm{CO}_{2}$ for a further $4 \mathrm{~h}$. The absorbance was measured at $450 \mathrm{~nm}$ using a microplate reader (Tecan, Männedorf, Switzerland) and cell viability was expressed as a percentage relative to that in the control group (100\%) with medium and DMSO (Wako) treatment not exposed to glutamate.

Measurement of acetylcholinesterase (AchE) activity. To measure AchE activity, the SH-SY5Y cells were treated with 5\% all-trans retinoic acid (RA; Sigma-Aldrich, St. Louis, MO, USA) to induce differentiation. The culture medium was replaced with fresh medium containing RA every 2 days until day 6 . On day 7, the differentiated cells were pre-treated with SBE for $1 \mathrm{~h}$ and the medium was exchanged for that containing glutamate with or without SBE. The cells were further incubated at $37^{\circ} \mathrm{C}$ with $5 \% \mathrm{CO}_{2}$ conditions for $3 \mathrm{~h}$. The cells were then washed with ice-cold phosphate buffered saline (PBS)3 times, lysed with $0.1 \mathrm{M}$ phosphate buffer $(\mathrm{pH} 7.5)$, centrifuged at $2,000 \mathrm{x}$ g for $10 \mathrm{~min}$, and the supernatant was collected. AchE activity was determined using commercial assay kits (Abnova, Taipei, Taiwan) and was calculated as the optical density (OD) at $412 \mathrm{~nm}$ per mg protein.

Total glutathione contents. Total intracellular glutathione contents were determined using a commercial assay kit (Cell Biolabs, San Diego, CA, USA) according to the manufacturer's protocol. The cells pre-treated with SBE for $1 \mathrm{~h}$ were changed to medium containing glutamate with or without SBE for $3 \mathrm{~h}$. The cells were then washed with ice-cold PBS, lysed using assay reagent and centrifuged at 2,000 x g for $10 \mathrm{~min}$. The supernatant was used to measure the glutathione contents as the sum of GSH and GSSG. The absorbance was measured at $405 \mathrm{~nm}$ using a microplate reader (Tecan) and total glutathione contents were expressed as a percentage relative to that in the control group (100\%).

4',6-Diamidino-2-phenylindole (DAPI) staining. Glutamateinduced nuclear morphological changes were assessed by DAPI staining (Sigma-Aldrich). Following glutamate treatment with and without sample, cells were washed with ice-cold PBS three times and fixed with 4\% paraformaldehyde in PBS for $10 \mathrm{~min}$. Fixed cells were washed with PBS and permeabilized with $0.25 \%$ Triton X-100 in PBS for $10 \mathrm{~min}$. After washing again with PBS, the cells were stained with DAPI staining solution for $10 \mathrm{~min}$ at room temperature. The stained cells were examined under a fluorescence microscope (x40 magnification; 

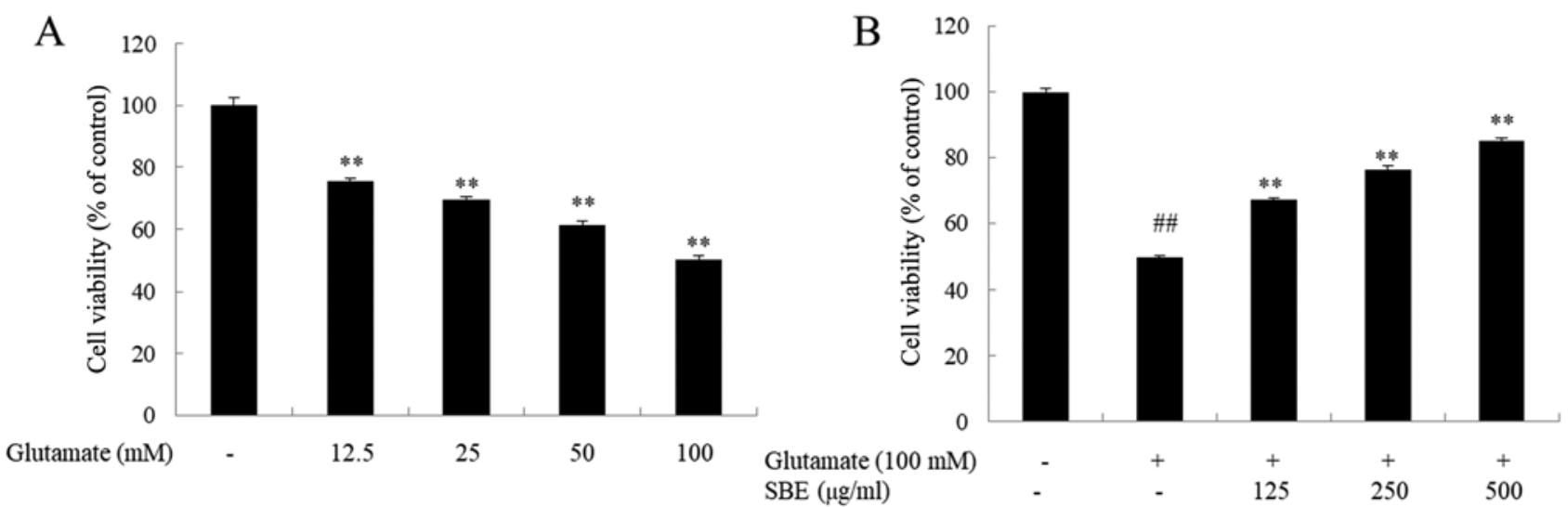

Figure 1. Protective effects of Scrophularia buergeriana extract (SBE) on glutamate-induced toxicity in SH-SY5Y cells. (A) Cells were exposed to various concentrations of glutamate $(12.5-100 \mathrm{mM})$ for $3 \mathrm{~h}$ and cell viability was measured using a commercial kit. (B) SH-SY5Y cells were pre-treated with SBE $(125-500 \mu \mathrm{g} / \mathrm{ml})$ for $1 \mathrm{~h}$ and then exposed to $100 \mathrm{mM}$ glutamate with or without SBE for $3 \mathrm{~h}$, before measuring cell viability. Cell viability was calculated as a percentage of that in the control group (100\%) and the results are expressed as the means \pm standard error of the mean (SEM) of independent experiments $(\mathrm{n}=3) .{ }^{*} \mathrm{P}<0.05$ and $^{* *} \mathrm{P}<0.01$ compared with the group exposed to glutamate only; ${ }^{\# \#} \mathrm{P}<0.01$ compared with the control (untreated) group.

Nikon, Tokyo, Japan) to confirm the presence of apoptotic cells exhibiting size-reduced nuclei, chromatin condensation, intense fluorescence and nuclear fragmentation. The number of apoptotic cells was expressed as a percentage relative to that in the control group (100\%).

Terminal deoxynucleotidyl transferase deoxyuridine triphosphate (dUTP) nick end labeling (TUNEL) assay. Glutamate-induced DNA damage was evaluated using a TUNEL assay commercial kit (BioVision, Milpitas, CA, USA) according to the manufacturer's instructions. The SH-SY5Y cells were seeded and incubated for $24 \mathrm{~h}$ in $5 \% \mathrm{CO}_{2}$ at $37^{\circ} \mathrm{C}$. The cells were then pre-treated with various concentrations $(125,250$ or $500 \mu \mathrm{g} / \mathrm{ml})$ of SBE for $1 \mathrm{~h}$ and exposed to $100 \mathrm{mM}$ glutamate for $3 \mathrm{~h}$ with or without SBE. The treated cells were washed with ice-cold PBS and fixed by the addition of $1 \%$ paraformaldehyde in PBS on ice for $15 \mathrm{~min}$. The cells were then treated with $70 \%$ ethanol (EtOH) for $30 \mathrm{~min}$ on ice and then washed 3 times with wash buffer. A total of $50 \mu \mathrm{l}$ staining solution contained with FICT-dUTP was added to the washed cells prior to incubation for $60 \mathrm{~min}$ at $37^{\circ} \mathrm{C}$. After staining, the cells were washed with rinse buffer 3 times and incubated with propidium iodide (PI)/RNase solution in the dark for $30 \mathrm{~min}$ at room temperature. The stained cells were analyzed under a fluorescence microscope (x20 magnification; Nikon).

Protein extraction and western blot analysis. The treated SH-SY5Y cells were lysed with radioimmunoprecipitation assay (RIPA) buffer [50 mM Tris- $\mathrm{HCl} \mathrm{pH} 7.4,150 \mathrm{mM}$ $\mathrm{NaCl}, 1 \mathrm{mM}$ ethylenediaminetetraacetic acid (EDTA), $1 \%$ Triton X-100, $1 \%$ sodium deoxycholate, $0.1 \%$ sodium dodecyl sulfate (SDS) and $1 \mathrm{mM}$ PMSE] and $1 \%$ protease inhibitor cocktail (Roche, Basel, Switzerland), followed by centrifugation at $2,000 \mathrm{xg}$ for $15 \mathrm{~min}$ at $4^{\circ} \mathrm{C}$. The supernatant was collected, and the protein concentration was assessed using a bicinchoninic acid (BCA) protein assay kit (Thermo Fisher Scientific). Equal amounts of protein (20 $\mu \mathrm{g} / \mathrm{lane})$ were separated by 10-15\% SDS-polyacrylamide gel electrophoresis and transferred onto polyvinylidene difluoride membranes
(Bio-Rad, Hercules, CA, USA). The membranes were blocked with commercial blocking buffer (Thermo Fisher Scientific) and washed 3 times with Tris-buffered saline containing $0.1 \%$ Tween-20 (TBST). After washing, the membranes were incubated at $4^{\circ} \mathrm{C}$ overnight with the following appropriate antibodies: SOD1 (1:1,000; cat. no. sc-515404), SOD2 (1:1,000; cat. no. sc-137254) (both from Santa Cruz Biotechnology, Santa Cruz, CA, USA), GPx-1 (1:1,000; cat. no. 3206), p-p38 (1:1,000; cat. no. 9211), p38 (1:1,000; cat. no. 8690), Bax (1:1,000; cat. no. 2772), Bcl-2 (1:1,000; cat. no. 3498), cleaved caspase-3 (1:1,000; cat. no. 9664), cleaved PARP (1:1,000; cat. no. 5625) and $\beta$-actin (1:2,000; cat. no. 8457) (all from Cell Signaling Technology, Danvers, MA, USA) washed 3 times with TBST, and incubated with horseradish peroxidase-conjugated secondary antibodies: goat anti-rabbit $(1: 1,000$; cat. no. SA002), goat anti-mouse (1:1,000; cat. no. SA001) (both from genDEPOT, Katy, TX, USA) for $1 \mathrm{~h}$ at room temperature. The membranes were washed 3 times and visualized via enhanced chemiluminescence (ATTO, Tokyo, Japan). Densitometry was performed using Image-Pro Plus software (6.0 version; Media Cybernetics, Inc., USA)

Statistical analysis. Data are expressed as the means \pm standard error of the mean (SEM) and were analyzed using SPSS Statistics 22.0 software (SPSS Inc., Chicago, IL, USA). Different treatment groups were compared using the Student's t-test and one-way analysis of variance (ANOVA) followed by multiple comparisons correction using Dunnett's post-hoc test using Origin 7.0 software (OriginLab, Northampton, MA, USA). Differences were considered statistically significant or highly significant at values of $\mathrm{P}<0.05$ and $\mathrm{P}<0.01$, respectively.

\section{Results}

Effects of SBE on glutamate-induced cell death and cytotoxicity in $\mathrm{SH}$-SY5Y cells. To investigate the protective effects on SBE against the glutamate-induced death of SH-SY5Y cells, we measured cell viability. To select the appropriate concentration of glutamate, the SH-SY5Y cells were exposed to various 
A

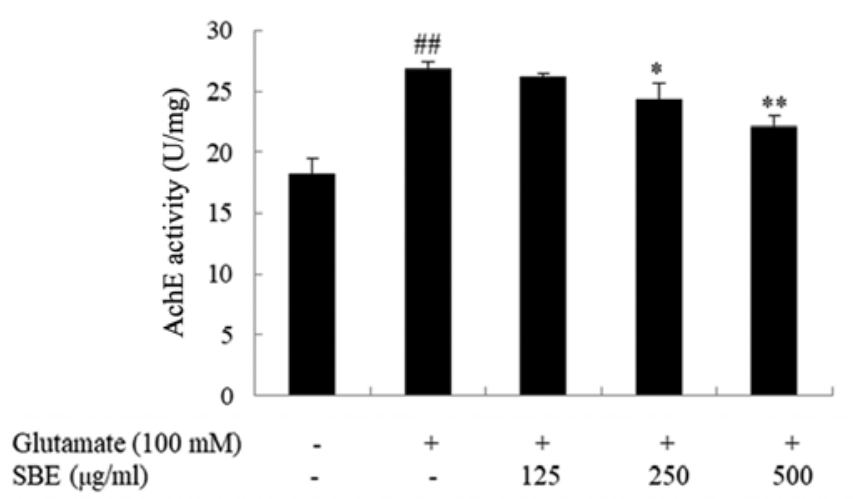

B

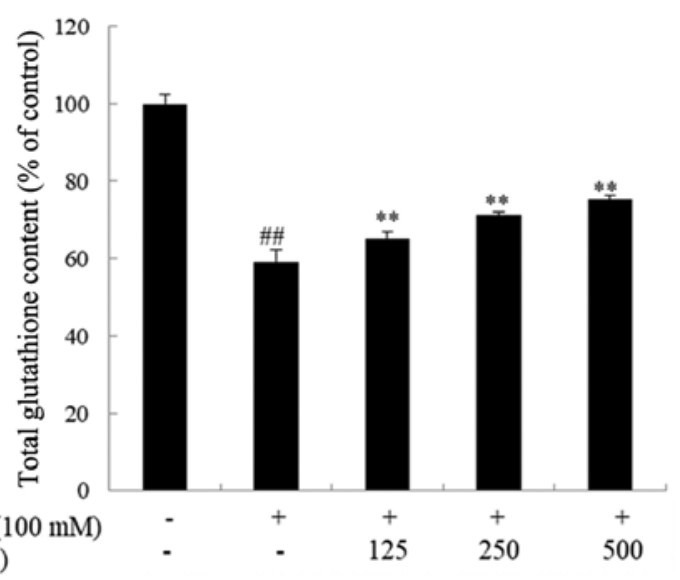

Figure 2. (A) Effects of Scrophularia buergeriana extract (SBE) on acetylcholine esterase (AchE) expression in SH-SY5Y cells. Cells were incubated with SBE for $1 \mathrm{~h}$ and then exposed to glutamate with or without SBE for $3 \mathrm{~h}$. Treated cells were lysed, and the supernatant was used to measurement AchE. The results were calculated as unit values per mg protein and are expressed as the means \pm SEM of independent experiments ( $=3$ ). ${ }^{*} \mathrm{P}<0.05$ and ${ }^{* *} \mathrm{P}<0.01$ compared with the group exposed to glutamate only; ${ }^{\# \#} \mathrm{P}<0.01$ compared with the control (untreated) group. (B) Effects of SBE on the total glutathione content in SH-SY5Y cells. Cells were incubated with SBE for $1 \mathrm{~h}$ and then exposed to glutamate with or without SBE for $3 \mathrm{~h}$. The supernatant of lysed cells was used for glutathione content measurement. Total glutathione content was calculated as a percentage of that in the control group (100\%) and expressed as the means \pm SEM of independent experiments $(\mathrm{n}=3) .{ }^{* *} \mathrm{P}<0.01$ compared with the group exposed to glutamate only; ${ }^{\# \#} \mathrm{P}<0.01$ compared with the control (untreated) group.

concentrations of glutamate for $3 \mathrm{~h}$. As shown in Fig. 1, exposure to $12.5-100 \mathrm{mM}$ glutamate dose-dependently decreased cell viability: Cell viability decreased by $50 \%$ following $3 \mathrm{~h}$ of exposure to $100 \mathrm{mM}$ glutamate compared to the group not exposed to glutamate. Conversely, the viability of the cells pre-treated with SBE for $1 \mathrm{~h}$ and exposed to glutamate increased by 18,27 and $36 \%$ compared to that of the cells exposed to glutamate only and not treated with SBE.

Inhibitory effects of SBE on AchE activity in glutamate-exposed SH-SY5Y cells. To confirm the neuroprotective effects of SBE, AchE activity was investigated in the SH-SY5Y cells with glutamate-induced neurotoxicity. As shown in Fig. 2A, AchE activity in the glutamate-exposed group was significantly higher than that in the control group. However, co-treatment with SBE dose-dependently decreased AchE activity. AchE activity in the groups treated with 250 and $500 \mu \mathrm{g} / \mathrm{ml} \mathrm{SBE}$ was reduced by 9.4 and $18.5 \%$, respectively, compared to that in the group exposed to glutamate only.

Effects of SBE on total glutathione content in the glutamate-induced apoptosis of SH-SY5Y cells. To evaluate the antioxidant effects of SBE, we measured the total glutathione content in the glutamate-exposed SH-SY5Y cells. As expected, and as shown in Fig. 2B, exposure to glutamate induced oxidative stress and markedly decreased the total glutathione contents in the cells compared to that in the control cells. However, the total glutathione contents in the SBE-treated cells were recovered in a dose-dependent manner. The total glutathione contents in the groups treated with 125, 250 and $500 \mu \mathrm{g} / \mathrm{ml} \mathrm{SBE}$ were increased by $9.3,17.1$ and $21.5 \%$, respectively, compared to those in the group exposed to glutamate only; these results provide evidence of the antioxidant effects of SBE.

SBE treatment attenuates the glutamate-induced apoptosis of SH-SY5Y cells. To observe the nuclear morphological changes following exposure to glutamate, the cells were stained with DAPI. As shown in Fig. 3A, the control cells exhibited regular oval shapes, whereas the glutamate-exposed cells displayed nuclear condensation and DNA fragmentation, and were unevenly stained. However, the number of DAPI-positive cells in the SBE-treated groups was significantly lower than that in the group not treated with SBE, and the glutamate-induced nuclear morphological changes were attenuated. Furthermore, we examined the anti-apoptotic effects of SBE on glutamate-induced cell death by confirming DNA fragmentation by TUNEL assay using PI and fluorescein isothiocyanate (FITC)-dUTP double staining. PI stains each cell including normal and apoptotic cells, whereas FITC-dUTP stains only apoptotic cells with DNA fragmentation. As shown in Fig. 3B, there were more FITC-dUTP-stained cells in the glutamate-exposed group than in the control group. However, the number of stained cells in the SBE-treated group decreased, indicating that SBE reduced glutamate-induced DNA fragmentation.

SBE inhibits glutamate-induced oxidative stress by regulating antioxidant enzyme expression in SH-SY5Y cells. To examine the antioxidant mechanisms of action of SBE, we examined the expression levels of antioxidant proteins, such as SOD1, SOD2, and GPX-1 in the SH-SY5Y cells undergoing glutamate-induced oxidative stress. As shown in Fig. 4, SOD1, SOD2 and GPX-1 protein expression decreased following exposure to glutamate compared to that in the control cells. However, SOD1 protein expression in the SBE-treated cells dose-dependently increased by 1.17-, 2.14- and 2.08-fold, respectively in the cells treated with 125,250 and $500 \mu \mathrm{g} / \mathrm{ml}$ $\mathrm{SBE}$, compared to that in the cells exposed to glutamate only and not treated with SBE. Furthermore, treatment with 125, 250 and $500 \mu \mathrm{g} / \mathrm{ml} \mathrm{SBE}$ increased SOD2 protein expression compared to that in the cells exposed to glutamate only and not treated with SBE. GPX-1 protein expression was significantly 

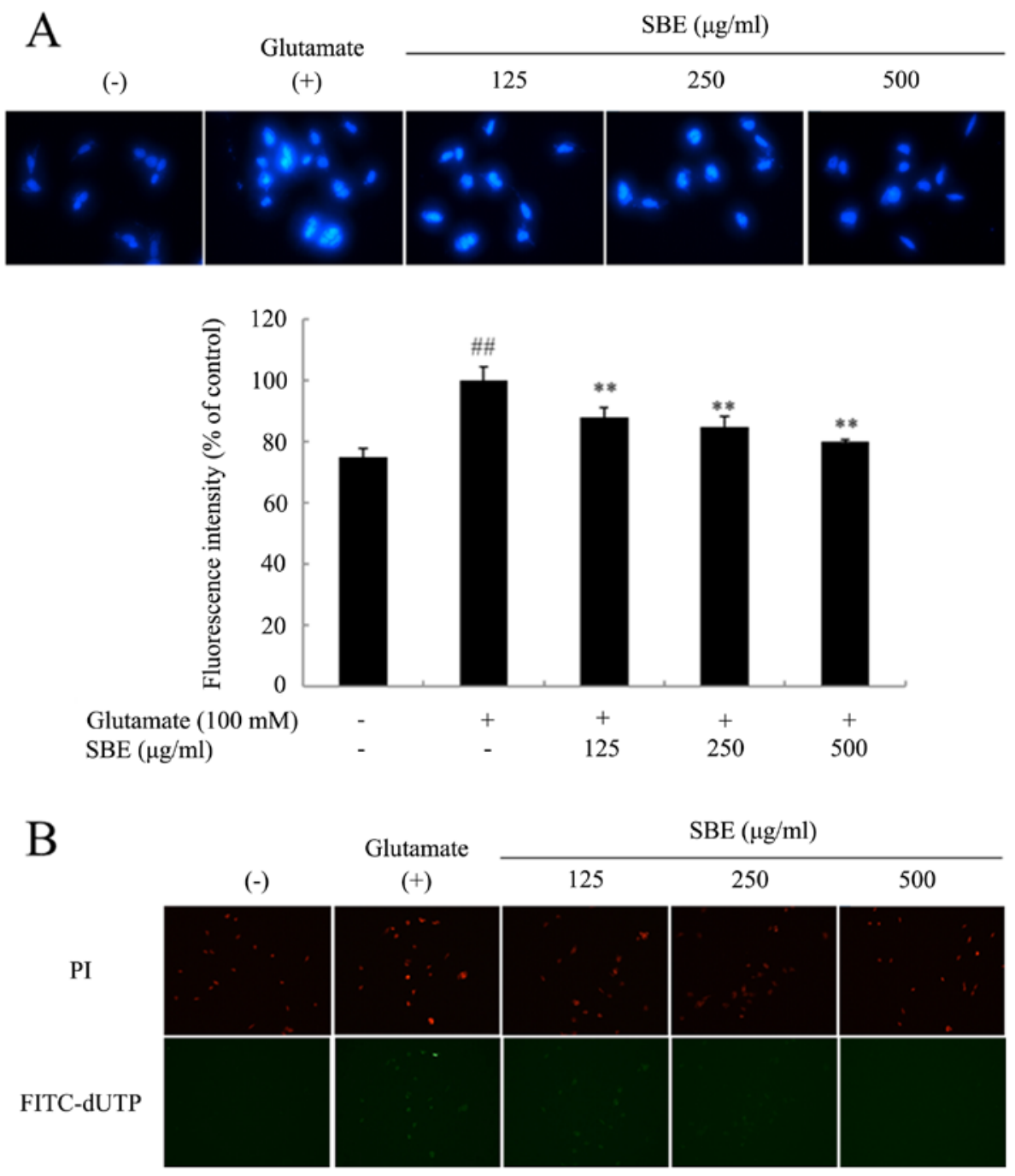

Figure 3. Effects of Scrophularia buergeriana extract (SBE) on glutamate-induced DNA fragmentation in SH-SY5Y cells. DNA fragmentation was assessed via (A) 4',6-diamidino-2-phenylindole (DAPI) staining and (B) terminal deoxynucleotidyl transferase deoxyuridine triphosphate (dUTP) nick end labeling (TUNEL) assay, using fluorescence microscopy. Fragmented nuclei and condensed DNA were examined via light microscopy for morphological analysis, and normal and apoptotic cells were shown as red through propidium iodide (PI)-staining. TUNEL-positive nuclei were stained green and this indicated DNA damage in apoptotic (PI- and FITC-positive) cells. The results from the quantitative analysis of DAPI staining are reported as the means \pm SEM of independent experiments $(\mathrm{n}=3)$. ${ }^{* *} \mathrm{P}<0.01$ compared with the group exposed to glutamate only; ${ }^{\# \#} \mathrm{P}<0.01$ compared with the control (untreated) group.

increased by SBE treatment compared to that in the control group. On the whole, these results demonstrate that SBE reduces glutamate-induced oxidative stress via the regulation of SOD1, SOD2 and GPx-1 protein expression, and enhances the expression of antioxidant enzymes.

SBE attenuates the glutamate-induced activation of $p 38$ MAPKs and apoptotic pathways in SH-SY5Y cells. To examine the anti-apoptotic mechanisms of action of SBE, we assessed the expression of apoptotic proteins associated with $\mathrm{p} 38$ MAPKs, such as B-cell lymphoma-2 (Bcl-2), Bcl-2-associated $X$ protein (Bax), cleaved caspase- 3 and cleaved poly (adenosine diphosphate (ADP)-ribose) polymerase (PARP) in glutamate-exposed SH-SY5Y cells by western blot analysis. As shown in Fig. 5, the levels of phosphorylated (p)-p38, Bax, cleaved caspase- 3 and cleaved PARP were upregulated in the glutamate-exposed group compared to those in the control group. By contrast, Bcl-2 expression was downregulated in the glutamate-exposed cells compared to that in the control cells. However, treatment with 250 and $500 \mu \mathrm{g} / \mathrm{ml} \mathrm{SBE}$ decreased the p-p38 protein expression levels compared to those in the cells exposed to glutamate only and not treated with SBE. Furthermore, treatment with SBE decreased Bax protein expression by 11,12 and $46 \%$ in the cells treated with 125,250 and $500 \mu \mathrm{g} / \mathrm{ml} \mathrm{SBE}$, and treatment with $500 \mu \mathrm{g} / \mathrm{ml}$ SBE increased Bcl-2 expression compared to that in the cells exposed to glutamate only and not treated with SBE. SBE treatment at 125,250 and $500 \mu \mathrm{g} / \mathrm{ml}$ also dose-dependently decreased glutamate-induced cleaved caspase- 3 protein expression by 19,50 and $67 \%$, respectively, compared to that in the cells exposed to glutamate only and not treated with SBE. Cleaved PARP protein expression was also significantly lower in the SBE-treated group compared to that in the cells exposed to glutamate only and not treated with SBE.

Treatment with SBE significantly decreased p-p38, Bax, cleaved caspase- 3 and cleaved PARP expression, and upregulated Bcl-2 expression. The relevant mechanisms of action of SBE in this study are summarized in Fig. 6. 
A

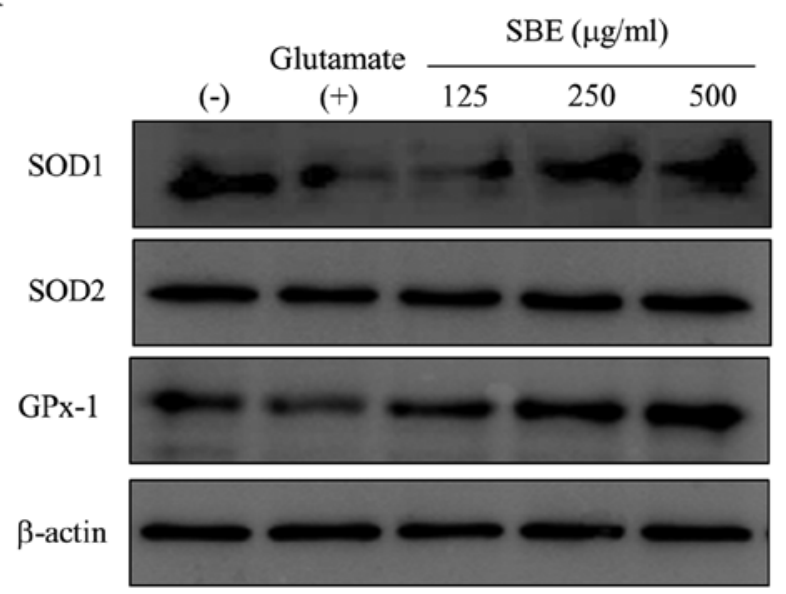

B

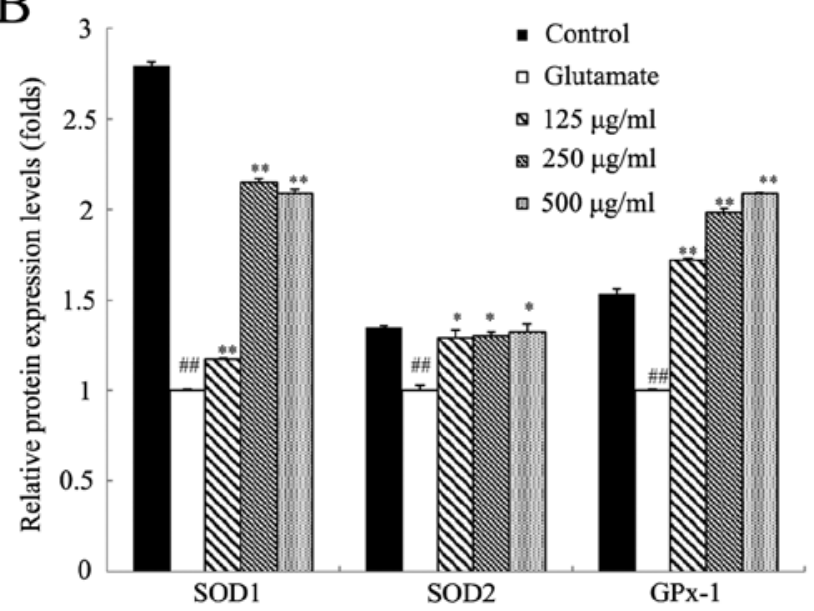

Figure 4. Effects of Scrophularia buergeriana extract (SBE) on antioxidant protein expression levels in SH-SY5Y cells. (A) The expression levels of superoxide dismutase (SOD)1, SOD2, and glutathione peroxidase-1 (GPx-1) were measured by western blot analysis. (B) The density of the protein bands was quantified and calculated using Image $J$ software. Protein expression levels were normalized to those of $\beta$-actin. The data are expressed as the means \pm SEM of independent experiments $(n=3) .{ }^{*} \mathrm{P}<0.05$ and ${ }^{* *} \mathrm{P}<0.01$ compared with the group exposed to glutamate only; ${ }^{\# \#} \mathrm{P}<0.01$ compared with the control (untreated) group.

A

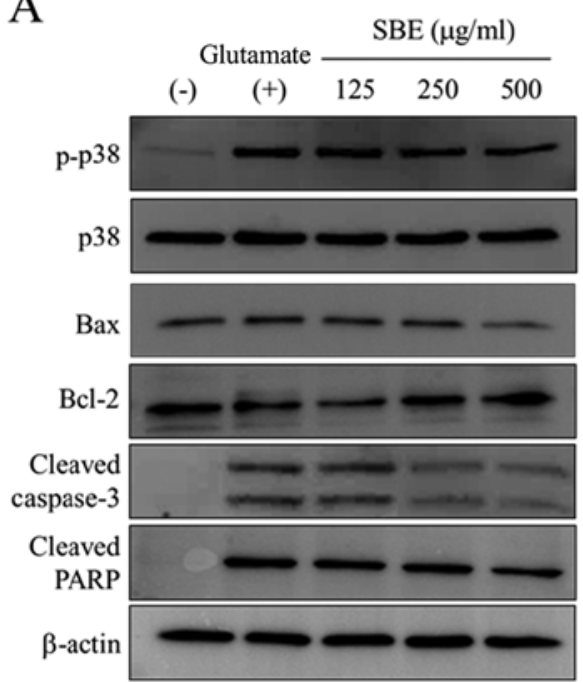

B

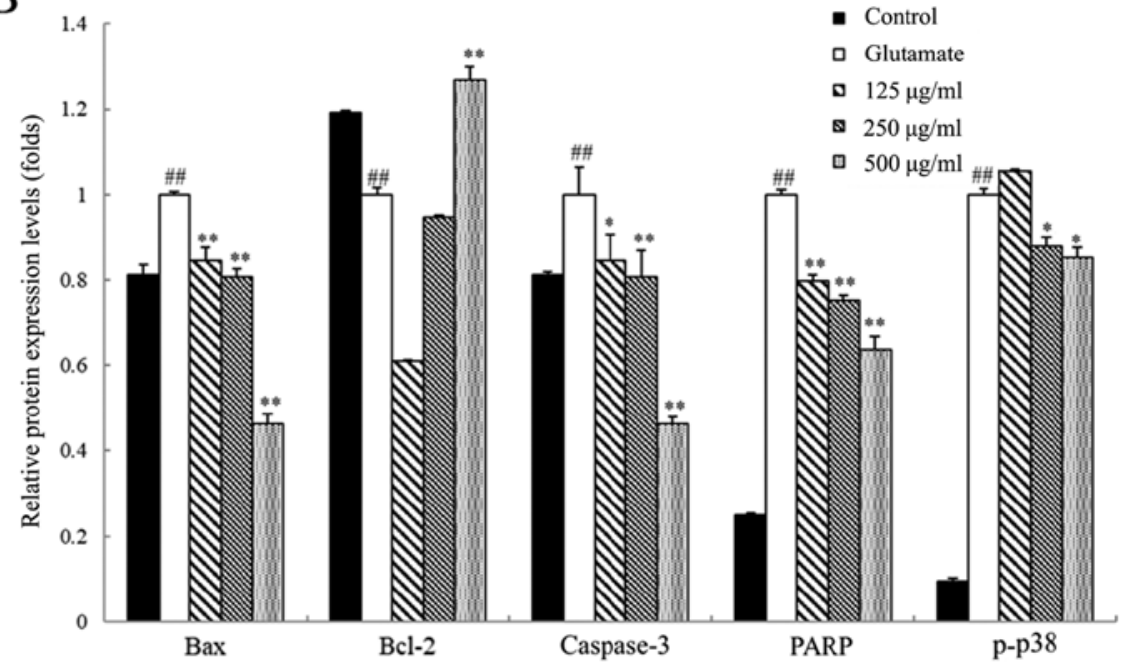

Figure 5. Effects of Scrophularia buergeriana extract (SBE) on apoptotic protein expression levels in SH-SY5Y cells. (A) The expression of phosphorylated (p)-p38, B-cell lymphoma-2 (Bcl-2), Bcl-2-associated X protein (Bax), cleaved caspase-3 and cleaved poly (adenosine diphosphate (ADP)-ribose) polymerase (PARP) was measured by western blot analysis. (B) The density of the protein bands was quantified and calculated using Image J software. p-p38 protein expression levels were normalized to those of $\mathrm{p} 38$, and other protein expression levels were normalized to those of $\beta$-actin. The data are expressed as the means \pm SEM of independent experiments $(\mathrm{n}=3)$. ${ }^{*} \mathrm{P}<0.05$ and ${ }^{* * *} \mathrm{P}<0.01$ compared with the group exposed to glutamate only; ${ }^{\# \#} \mathrm{P}<0.01$ compared with the control (untreated) group.

\section{Discussion}

Glutamate is an excitatory amino acid neurotransmitter. It is involved in several physiological processes and mediates brain function, including cognition, memory and learning $(28,29)$. However, glutamate induces oxidative stress and neurotoxicity, and may lead to the development of various neurodegenerative diseases when present at high concentrations. Oxidative stress is considered to be a key factor that leads to neuronal loss and death (30). In glutamate-induced cell death, glutamate plays a role in the inhibition of glutathione synthesis and depletion, which induces the excessive production of ROS, resulting in oxidative stress $(31,32)$. The accumulation of excessive ROS leads to structural and functional changes in the mitochondria and activates cell death pathways (32).

SB is a black plant with a strong scent, whose roots are used in oriental medicine. The roots of SB have been reported to possess anti-allergic (33), immune-protective (34) and antioxidant activities (35), and compounds isolated from SB roots such as MCA have been reported to have neuro-protective effects. Therefore, we hypothesized that SBE may also inhibit the apoptotic process by exerting antioxidant effects.

SH-SY5Y neuroblastoma cells have been used as an excitotoxic in vitro model following exposure to high concentrations of exogenous glutamate. SH-SY5Y cells may be useful in exploring excitatory amino acid-induced processes as they 

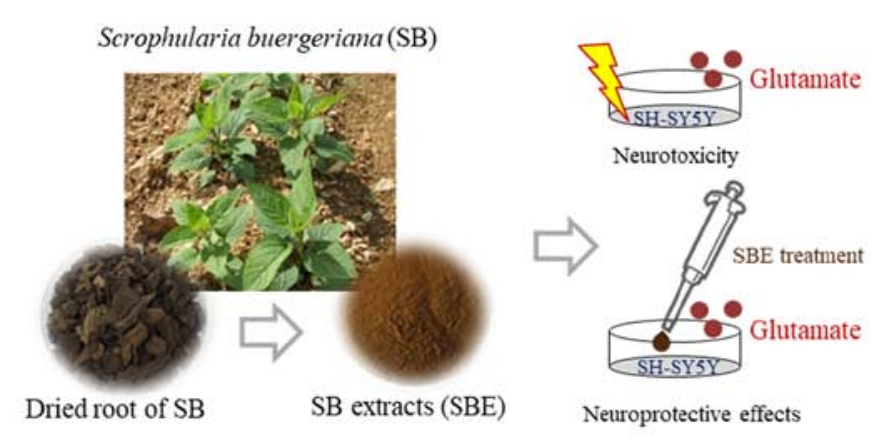

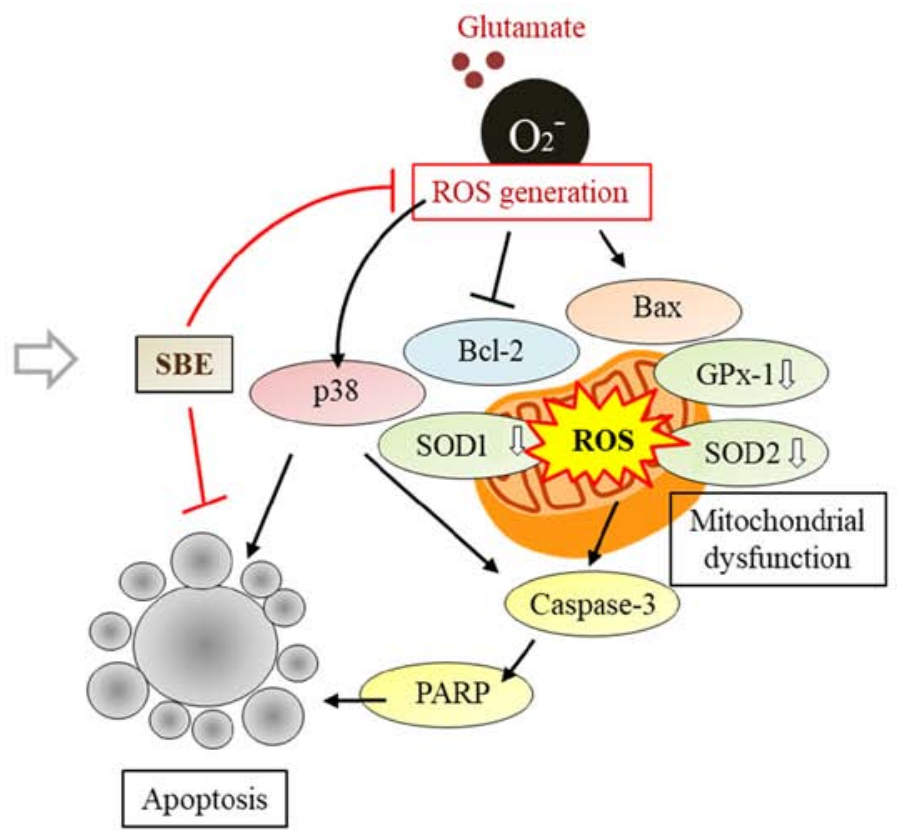

Figure 6. Schematic view of Scrophularia buergeriana extract (SBE) regulating reactive oxygen species (ROS) levels and the apoptotic signaling cascade. Excessive glutamate caused ROS generation and induces neuronal cell apoptosis. The generated ROS triggers p38 and Bcl-2-associated X protein (Bax) protein and damage to mitochondrial function. The activated caspase-3 and poly (adenosine diphosphate (ADP)-ribose) polymerase (PARP) proteins result in apoptosis. SBE treatment reduces the production of ROS by regulating the expression of enzymes, including superoxide dismutase (SOD)1, SOD2 and glutathione peroxidase-1 (GPx-1) and also inhibits the apoptotic pathway.

express both ionotropic and metabotropic receptors $(29,36)$. Therefore, in this study, we examined whether treatment with SBE would exert antioxidant effects and prevent the apoptosis of SH-SY5Y cells induced by glutamate-induced cytotoxicity.

The present study demonstrated that glutamate reduced cell viability, whereas SBE treatment significantly inhibited cell death caused by glutamate as a measurement of cell viability. Cell viability is used as an indication of cell death. To examine the neuroprotective effects of SBE, we also assessed AchE activity. AchE hydrolyzes acetylcholine to choline and acetate and is an essential enzyme responsible for the inactivation of the neurotransmitter acetylcholine. It maintains normal function of the nervous system. However the problems in synaptic integrity, neurite outgrowth and neurodevelopment are observed, and apoptosis is induced when AchE concentrations are high (37). Therefore, it is important to consider low AchE levels as a marker of neurotoxicity. In this study, we confirmed that glutamate caused cytotoxicity by increasing AchE expression, although SBE treatment inhibited AchE activity compared to that in the SH-SY5Y cells exposed to glutamate only, consistent with the results from a previous study (23). To confirm the antioxidant activity of SBE, we evaluated the total glutathione contents. Glutathione is known as a neuronal antioxidant essential for the removal of ROS and the reduction of oxidative stress. Excessive glutamate indicates the depletion of glutathione, which is caused by inhibiting cysteine uptake (38). In this study, glutamate treatment significantly decrease dthe glutathione contents. However, SBE treatment upregulated the glutathione contents compared to those in the cells exposed to glutamate only and not treated with SBE. Furthermore, we evaluated the expression of antioxidant enzymes, such as SOD1, SOD2 and GPx-1, which scavenge free radicals (39). SOD converts superoxide radicals $\left(\mathrm{O}_{2-}\right)$ to
$\mathrm{H}_{2} \mathrm{O}_{2}$, which is converted to $\mathrm{H}_{2} \mathrm{O}$ by GPx in the cytosol (40). These results suggest that the SBE protects against oxidative neuronal damage by exerting antioxidant effects.

ROS causes DNA damage and nuclear fragmentation, and leads to abortive apoptosis that can be detected by TUNEL assay and DAPI staining (41). Therefore, in this study, we investigated whether SBE inhibits oxidative stress-induced DNA impairment and cell death. The findings of this study demonstrated that SBE attenuated glutamate-induced cell death by inhibiting nuclear condensation, and DNA fragmentation and degradation.

In this study, we also demonstrated that SBE significantly inhibited the glutamate-induced activation of caspase-related proteins. Caspase is known as an apoptotic effector and is regulated by pro- and antiapoptotic $\mathrm{Bcl}-2$ family proteins. Glutamate-induced ROS production affects mitochondrial function by releasing caspase activators (42). Previous studies have reported that p38 kinases induce apoptosis and increase caspase-3 expression, thus leading to PARP activation $(43,44)$. In this study, we confirmed that exposure to glutamate induced an increase in the levels of p-p38, Bax, cleaved caspase-3 and cleaved PARP, and induced a decrease in Bcl-2 levels by promoting the apoptotic pathway $(45,46)$. The relevant mechanisms of action of SBE in this study are summarized in Fig. 6.

Taken together, the results of the present study demonstrate that SBE exerts neuroprotective effects against glutamate-induced toxicity in SH-SY5Y cells by removing ROS and reducing oxidative stress through the increased expression of antioxidant enzymes and the inhibition of DNA impairment. SBE also displayed anti-apoptotic activity by downregulating Bax, cleaved caspase-3 and cleaved PARP expression via the inhibition of p38 MAPKs. Thus, the findings of this study suggest that SBE may be used as a functional 
food for attenuating memory impairment through its antioxidant and anti-apoptotic activities.

\section{Acknowledgements}

Not applicable.

\section{Funding}

This study was carried out with the support of the 'Cooperative Research Program for Agriculture Science and Technology Development (Project no. PJ013215012019)', Rural Development Administration, Republic of Korea.

\section{Availability of data and materials}

The analyzed datasets generated during the study are available from the corresponding author on reasonable request.

\section{Authors' contributions}

HJL analyzed the experimental data and optimized the SH-SY5Y cell cultures. DM and BNI performed the data processing and quality control assessment. DAS contributed to the conception and design of the study, provided critical comments and revised the manuscript. AT and SHY designed the project, and contributed to the analysis of the data and finalization of the manuscript. All authors have read and approved the final manuscript.

\section{Ethics approval and consent to participate}

Not applicable.

\section{Patient consent for publication}

Not applicable.

\section{Competing interests}

DAS is the Editor-in-Chief for the journal, but had no personal involvement in the reviewing process, or any influence in terms of adjudicating on the final decision, for this article. The other authors declare that they have no competing interests.

\section{References}

1. Kawasaki H, Morooka T, Shimohama S, Kimura J, Hirano T, Gotoh Y and Nishida E: Activation and involvement of p38 mitogen-activated protein kinase in glutamate-induced apoptosis in rat cerebellar granule cells. J Biol Chem 272: 18518-18521, 1997.

2. Nampoothiri M,Reddy ND, John J1,Kumar N, Kutty Nampurath G and Rao Chamallamudi M: Insulin blocks glutamate-induced neurotoxicity in differentiated SH-SY5Y neuronal cells. Behav Neurol 2014: 674164, 2014.

3. Çomaklı S, Sevim Ç, Kontadakis G, Doğan E, Taghizadehghalehjoughi A, Özkaraca M, Aschner M, Nikolouzakis TK and Tsatsakis A: Acute glufosinate-based herbicide treatment in rats leads to increased ocular interleukin-1 $\beta$ and c-Fos protein levels, as well as intraocular pressure. Toxicol Rep 6: 155-160, 2019.

4. Atlante A, Calissano P, Bobba A, Giannattasio S, Marra E and Passarella S: Glutamate neurotoxicity, oxidative stress and mitochondria. FEBS Lett 497: 1-5, 2001.
5. Gubandru M, Margina D, Tsitsimpikou C, Goutzourelas N, Tsarouhas K, Ilie M, Tsatsakis AM and Kouretas D: Alzheimer's disease treated patients showed different patterns for oxidative stress and inflammation markers. Food Chem Toxicol 61: 209-214, 2013.

6. Doble A: The role of excitotoxicity in neurodegenerative disease: Implications for therapy. Pharmacol Ther 81: 163-221, 1999.

7. Hynd MR, Scott HL and Dodd PR: Glutamate-mediated excitotoxicity and neurodegeneration in Alzheimer's disease. Neurochem Int 45: 583-595, 2004.

8. Blandini F, Greenamyre JT and Nappi G: The role of glutamate in the pathophysiology of Parkinson's disease. Funct Neurol 11: 3-15, 1996.

9. Zeron MM, Chen N, Moshaver A, Lee AT, Wellington CL, Hayden MR and Raymond LA: Mutant huntingtin enhances excitotoxic cell death. Mol Cell Neurosci 17: 41-53, 2001.

10. Jia J, Zhang L, Shi X, Wu M, Zhou X, Liu X and Huo T: SOD2 Mediates amifostine-induced protection against glutamate in PC12 cells. Oxid Med Cell Longev 2016: 4202437, 2016.

11. Jin L, Li D, Alesi GN, Fan J, Kang HB, Lu Z, Boggon TJ, Jin P, Yi H, Wright ER, et al: Glutamate dehydrogenase 1 signals through antioxidant glutathione peroxidase 1 to regulate redox homeostasis and tumor growth. Cancer Cell 27: 257-270, 2015.

12. Matsuda S, Nakagawa Y, Tsuji A, Kitagishi Y, Nakanishi A and Murai T: Implications of PI3K/AKT/PTEN signaling on superoxide dismutases expression and in the pathogenesis of Alzheimer's disease. Diseases 6: 28, 2018.

13. Goutzourelas N, Stagos D, Housmekeridou A, Karapouliou C, Kerasioti E, Aligiannis N, Skaltsounis AL, Spandidos DA, Tsatsakis AM and Kouretas D: Grape pomace extract exerts antioxidant effects through an increase in GCS levels and GST activity in muscle and endothelial cells. Int J Mol Med 36: 433-441, 2015.

14. Li Y, Maher P and Schubert D: Requirement for cGMP in nerve cell death caused by glutathione depletion. J Cell Biol 139: 1317-1324, 1997.

15. Kouka P, Chatzieffraimidi GA, Raftis G, Stagos D, Angelis A, Stathopoulos P, Xynos N, Skaltsounis AL, Tsatsakis AM and Kouretas D: Antioxidant effects of an olive oil total polyphenolic fraction from a Greek Olea europaea variety in different cell cultures. Phytomedicine 47: 135-142, 2018.

16. Margină D, Olaru OT, Ilie M, Grădinaru D, GuȚu C, Voicu S, Dinischiotu A, Spandidos DA and Tsatsakis AM: Assessment of the potential health benefits of certain total extracts from Vitis vinifera, Aesculus hyppocastanum and Curcuma longa. Exp Ther Med 10: 1681-1688, 2015.

17. Son Y, Cheong YK, Kim NH, Chung HT, Kang DG and Pae HO: Mitogen-activated protein kinases and reactive oxygen species: How can ROS activate MAPK pathways? J Signal Transduct 2011: 792639, 2011

18. Choi DJ, Cho S, Seo JY, Lee HB and Park YI: Neuroprotective effects of the Phellinus linteus ethyl acetate extract against $\mathrm{H}_{2} \mathrm{O}_{2}$-induced apoptotic cell death of SK-N-MC cells. Nutr Res 36: 31-43, 2016.

19. Cowan KJ and Storey KB: Mitogen-activated protein kinases: New signaling pathways functioning in cellular responses to environmental stress. J Exp Biol 206: 1107-1115, 2003.

20. Nakagami H, Morishita R, Yamamoto K, Yoshimura SI, Taniyama Y, Aoki M, Matsubara H, Kim S, Kaneda Y and Ogihara T: Phosphorylation of p38 mitogen-activated protein kinase downstream of bax-caspase-3 pathway leads to cell death induced by high D-glucose in human endothelial cells. Diabetes 50: 1472-1481, 2001.

21. Son Y, Cheong YK, Kim NH, Chung HT, Kang DG and Pae HO: Mitogen-activated protein kinases and reactive oxygen species: How can ROS activate MAPK pathway? J Signal Transduct 2011: 792639, 2011.

22. Cheung EC and Slack RS: Emerging role for ERK as a key regulator of neuronal apoptosis. Sci STKE 2004: PE45, 2004.

23. Jeong EJ, Ma CJ, Lee KY, Kim SH, Sung SH and Kim YC: KD-501, a standardized extract of Scrophularia buergeriana has both cognitive-enhancing and antioxidant activities in mice given scopolamine. J Ethnopharmacol 121: 98-105, 2009.

24. Kim SR, Sung SH, Jang YP, Markelonis GJ, Oh TH and Kim YC: E-p-methoxycinnamic acid protects cultured neuronal cells against neurotoxicity induced by glutamate. Br J Pharmacol 135: 1281-1291, 2002.

25. Kim SR, Koo KA, Sung SH, Ma CJ, Yoon JS and Kim YC: Iridois from Scrophularia buergeriana attenuate glutamate-induced neurotoxicity in rat cortical cultures. J Neurosci Res 74: 948-55, 2003. 
26. Jeong EJ, Lee KY, Kim SH, Sung SH and Kim YC: Cognitiveenhancing and antioxidant activities of iridoid glycosides from Scrophularia buergeriana in scopolamine-treated mice. Eur J Pharmacol 588: 78-84, 2008.

27. Kim SR, Kang SY, Lee KY, Kim SH, Markelonis GJ, Oh TH and Kim YC: Anti-amnestic activity of E-p-methoxycinnamic acid from Scrophularia buergeriana. Brain Res Cogn Brain Res 17: 454-461, 2003.

28. Hu Y, Li J, Liu P, Chen X, Guo DH, Li QS and Rahman K: Protection of SH-SY5Y cells from glutamine-induced apoptosis by 3,6'-disinapoyl sucrose, a bioactive compound isolated from radix polygala. J Biomed Biotechnol 2012: 1-5, 2012.

29. Al Mamun A, Hashimoto M, Katakura M, Hossain S and Shido O: Neuroprotective effect of thymoquinone against glutamate-induced toxicity in SH-SY5Y cells. Curr Top Nutraceutical Res 13: 143-152, 2015.

30. Song JH, Kang KS and Choi YK: Protective effect of casuarinin against glutamate-induced apoptosis in HT22 cells through inhibition of oxidative stress-mediated MAPK phosphorylation. Bioorg Med Chem Lett 27: 5109-5113, 2017.

31. Bak DH, Kim HD, Kim YO, Park CG, Han SY and Kim JJ: Neuroprotective effects of 20(S)-protopanaxadiol against glutamate-induced mitochondrial dysfunction in PC12 cells. Int J Mol Med 37: 378-386, 2016.

32. Kumari S, Mehta SL and Li PA: Glutamate induces mitochondrial dynamic imbalance and autophagy activation: Preventive effects of selenium. PLoS One 7: e39382, 2012.

33. Kim JK, Kim YH, Lee HH, Lim SS and Park KW: Effect of Scrophularia buergeriana extract on the degranulation of mast cells and ear swelling induced by dinitrofluorobenzene in mice. Inflammation 35: 183-191, 2012.

34. Ki SJ, Park JS, Myung NY, Moon PD, Choi IY, An HJ, Kim NH, Na HJ, Kim DH, Min-cheol K, et al: Scrophularia buergeriana regulates cytokine production in vitro. Immunopharmacol Immunotoxicol 31: 246-252, 2009.

35. Jeong J, Wahyudi LD, Keum YS, Yang H and Kim JH: E-p-Me thoxycinnamoyl- $\alpha$-l-rhamnopyranosyl ester, a phenylpropanoid isolated from Scrophularia buergeriana, increases nuclear factor erythroid-derived 2-related factor 2 stability by inhibiting ubiquitination in human keratinocytes. Molecules 23: 768, 2018.

36. Naarala J, Nykvist P, Tuomala M and Savolainen K: Excitatory amino acid-induced slow biphasic responses of free intracellular calcium in human neuroblastoma cells. FEBS Lett 330: 222-226, 1993.
37. Kalafatakis K, Gkanti V, Mackenzie-Gray Scott CA, Zarros A, Baillie GS and Tsakiris S: Acetylcholinesterase activity as a neurotoxicity marker within the context of experimentallysimulated hyperprolinaemia: An in vitro approach. J Nat Sci Biol Med 6 (Suppl 1): S98-S101, 2015.

38. Engin AB, Engin ED, Golokhvast K, Spandidos DA and Tsatsakis AM: Glutamate mediated effects of caffeine and interferon $\gamma$ on mercury-induced toxicity. Int J Mol Med 39: 1215-1223, 2017.

39. Chan PH: Role of oxidants in ischemic brain damage. Stroke 27 1124-1129, 1996.

40. Dröge W: Free radicals in the physiological control of cell function. Physiol Rev 82: 47-95, 2002.

41. Fu YB, Ahmed Z, Yang H and Horbach C: TUNEL assay and DAPI staining revealed few alterations of cellular morphology in naturally and artificially aged seeds of cultivated flax. Plants Basel 7: 34, 2018.

42. Chen S, Sun M, Zhao X, Yang Z, Liu W, Cao J, Qiao Y, Luo $X$ and Wen A: Neuroprotection of hydroxysafflor yellow $\mathrm{A}$ in experimental cerebrai ischemia/reperfusion injury via metabolic inhibition of phenylalanine and mitochondrial biogenesis. Mol Med Rep: Feb 15, 2019 (Epub ahead of print). doi: $10.3892 / \mathrm{mmr} .2019 .9959$

43. Juo P, Kuo CJ, Reynolds SE, Konz RF, Raingeaud J, Davis RJ, Biemann HP and Blenis J: Fas activation of the p38 mitogen-activated protein kinase signalling pathway requires ICE/CED-3 family proteases. Mol Cell Biol 17: 24-35, 1997.

44. Thornberry NA and Lazebnik Y: Caspases: Enemies within. Science 281: 1312-1316, 1998.

45. Teng H, Huang Q and Chen L: Inhibition of cell proliferation and triggering of apoptosis by agrimonolide through MAP kinase (ERK and p38) pathways in human gastric cancer AGS cells. Food Funct 7: 4605-4613, 2016.

46. Ya H, Wang X, Chen X, Jing Z, Ai X, Liang Y, Yu Y, Yi Z, Meng X, Meng $X$, et al: Establishment and evaluation of a simulated high-altitude hypoxic brain injury model in SD rats. Mol Med Rep 19: 2758-2766, 2019. International (CC BY-NC-ND 4.0) License. 